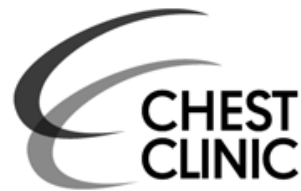

'Department of Pulmonology, University Medical Center Groningen, University of Groningen, Groningen, The Netherlands

${ }^{2}$ GRIAC Research Center, Groningen, The Netherlands ${ }^{3}$ Department of Respiratory Medicine, Ghent University Hospital, Ghent, Belgium ${ }^{4}$ Imperial College and Royal Brompton Hospital, London, UK ${ }^{5}$ Human and Development and Health, Faculty of Medicine, University of Southampton, Southampton, UK

\section{Correspondence to}

Professor Dirkje S Postma, Department of Pulmonology, University Medical Center Groningen, Hanzeplein 1, 9713 GZ Groningen, The Netherlands; d.s.postma@long.umcg.nl

Received 6 July 2011 Accepted 19 July 2011 Published Online First 25 August 2011

\title{
I have taken my umbrella, so of course it does not rain
}

\author{
D S Postma, ${ }^{1,2}$ G Brusselle, ${ }^{3}$ A Bush, ${ }^{4}$ J W Holloway ${ }^{5}$
}

\section{ABSTRACT}

Spirometry is used worldwide to diagnose respiratory disease, and it is a validated measure to assess airway obstruction. Irreversible airway obstruction is the defining feature of chronic obstructive pulmonary disease (COPD). Thus, an $\mathrm{FEV}_{1} / \mathrm{FVC}$ ratio $<70 \%$ is used to diagnose $\mathrm{COPD}$, and the severity is thereafter based on the level of $\mathrm{FEV}_{1}$. This definition is widely used in clinical practice and research, yet may lead to confusion with respect to the diagnosis associated with the presence of airway obstruction. The three main reasons are the following: (1) fixed airflow obstruction may be the result of specific diagnoses such as cystic fibrosis; (2) FEV $1 / F V$ ratio changes with ageing, and it is therefore inappropriate to use the same ratio at 40 and 90 years, leaving aside gender differences; (3) even when specific diagnoses are excluded, fixed airflow obstruction may be the end-stage of many different underlying processes. The authors believe that they have strong arguments that a COPD diagnosis based solely on spirometric values is nonsense. More sophisticated lung function tests, such as plethysmography, forced oscillation and lung clearance index, may help further to delineate the characteristics of low lung function. However, these are not feasible in most clinical contexts and in epidemiologic studies. Therefore, the authors throw down the gauntlet: spirometry is an essential tool in patient evaluation but dangerous for disease diagnosis, and the term COPD should only be used in the appropriate clinical (diagnostic) context.

\section{OPINION}

Spirometry is used worldwide to diagnose respiratory disease, and it is a validated measure to assess airway obstruction. ${ }^{1}$ Irreversible airway obstruction is the defining feature of chronic obstructive pulmonary disease (COPD). Thus, an $\mathrm{FEV}_{1} / \mathrm{FVC}$ ratio $<70 \%$ is used to diagnose COPD, and the severity is thereafter based on the level of $\mathrm{FEV}_{1}{ }^{2}{ }^{2}$ This definition is widely used in clinical practice and research, yet may lead to confusion with respect to the diagnosis associated with the presence of airway obstruction. The three main reasons are the following: (1) fixed airflow obstruction may be the result of specific diagnoses such as cystic fibrosis $(\mathrm{CF})^{3}$; (2) $\mathrm{FEV}_{1} / \mathrm{FVC}$ ratio changes with ageing, and it is therefore inappropriate to use the same ratio at 40 and 90 years, leaving aside gender differences ${ }^{45}$; and (3) even when specific diagnoses are excluded, fixed airflow obstruction may be the end-stage of many different underlying processes. ${ }^{6}$ We believe that we have strong arguments that a COPD diagnosis based solely on spirometric values is nonsense.

With regard to diagnosis, fixed airflow obstruction is a feature of many diseases, such as CF, primary

\section{Key messages}

What is the key question?

- What is the use of irreversible airway obstruction for a chronic obstructive pulmonary disease diagnosis?

\section{What is the bottom line?}

- Spirometry is an essential tool in patient evaluation but dangerous for disease diagnosis, and the term chronic obstructive pulmonary disease should only be used in the appropriate clinical (diagnostic) context.

\section{Why read on?}

- Spirometry is being used for disease diagnosis, but is this a valid tool?

ciliary dyskinesia and non-CF bronchiectasis. ${ }^{3}$ Children with CF died young in the past but may live in this era into middle age and beyond as a result of earlier disease diagnosis and better treatment options being available. They develop airway obstruction with advanced disease frequently comparable with the spirometric values found in COPD. ${ }^{7}$ Does this then mean that patients with CF develop COPD if they live long enough? Does this imply that doctors should change from CF to COPD treatment protocols? Rightly, as clinicians, we do not do this. The more surprising is that this is what we seem to do to patients with asthma. When an adult patient with lifelong asthma comes into a hospital to be treated for an asthma lung attack, ${ }^{8}$ the patient may be discharged with a diagnosis of COPD because irreversible airway obstruction is present, yet this has been shown not only to occur in COPD but in longstanding asthma as well. ${ }^{59}$ This is important because patients with asthma need not only long-acting bronchodilators but also inhaled steroids, the mainstay of asthma treatment. Thus, this change in diagnosis, particularly when the level of $\mathrm{FEV}_{1}$ is above the $50 \%$ predicted, may not serve these patients well.

In addition, there exists 'non-smoking' COPD that is attributed to biomass fuel exposure. ${ }^{10}$ One can assume that this will not have the same patterns of inflammation as COPD in smokers. There has been much speculation that the survivors of premature birth and bronchopulmonary dysplasia may be at risk for COPD, but such evidence as exists is that they do not have airway inflammation. ${ }^{11}$ Thus, treatment strategies trialled in patients with 'smoking COPD' may be inappropriate in other forms of persistent airflow obstruction. 
Figure 1 Simplified scheme of classification of individuals based upon $\mathrm{FEV}_{1}$ and $\mathrm{FEV}_{1} / \mathrm{FVC}$ ratio. Only in the appropriate clinical context, subjects with a post-bronchodilator $\mathrm{FEV}_{1} / \mathrm{FVC}$ $<70 \%$ (Global Initiative for Obstructive Lung Disease (GOLD)) or $<$ lower limit of normal, can be diagnosed with COPD (GOLD stage I if $\mathrm{FEV}_{1}>80 \%$; GOLD stage II, III or IV if $\mathrm{FEV}_{1}<80 \%,<50 \%$ or $<30 \%$, respectively).

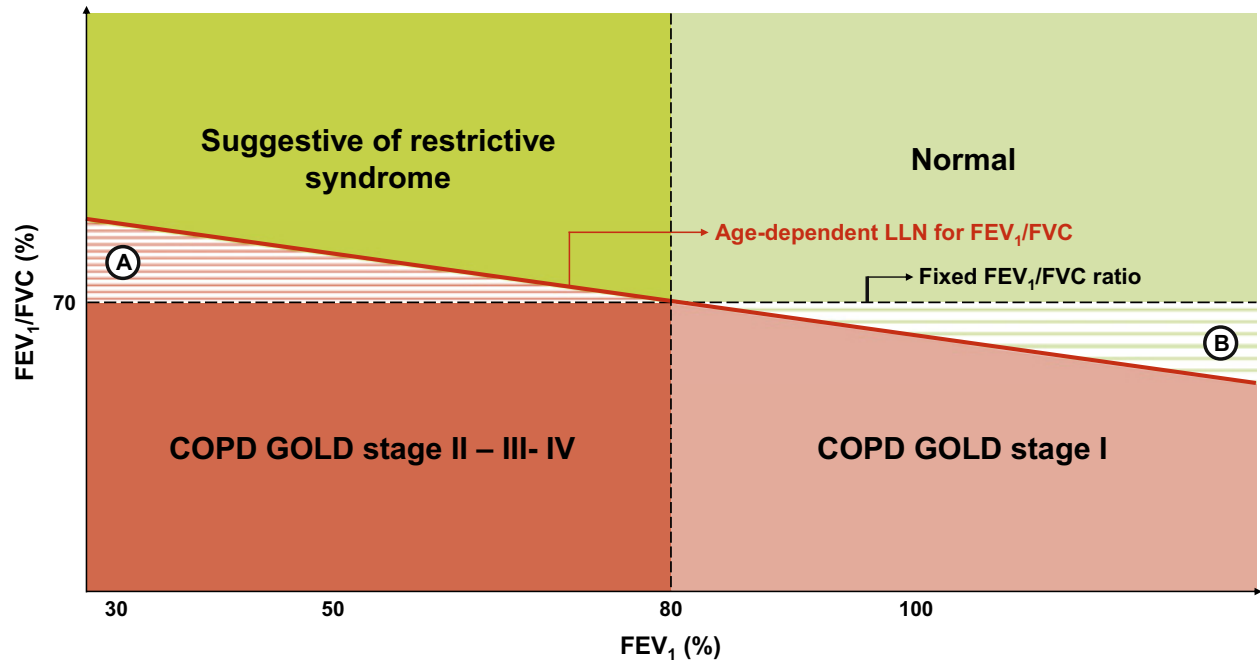

2. irreversible airway obstruction with a strong history of smoking;

3. irreversible airway obstruction compatible with previous low birth weight.

Obviously, more sophisticated lung function tests, such as plethysmography, forced oscillation and lung clearance index, may help further to delineate the characteristics of low lung function. However, these are not feasible in most clinical contexts and in epidemiologic studies. Therefore, we throw down the gauntlet: spirometry is an essential tool in patient evaluation but dangerous for disease diagnosis, and the term COPD should only be used in the appropriate clinical (diagnostic) context.

\section{Competing interests None.}

Contributors All authors discussed the content of the paper, wrote the article and approved the final version of this manuscript.

Provenance and peer review Not commissioned; internally peer reviewed.

\section{REFERENCES}

1. Lange P. Spirometric findings as predictors of survival. Thorax 2011;66:1-2.

2. Pauwels R, Buist A, Calverley P. Global strategy for the diagnosis, management, and prevention of chronic obstructive pulmonary disease. NHLBI/WHO Global Initiative for Chronic Obstructive Lung Disease (GOLD) Workshop summary. Am J Respir Crit Care Med 2009;163:1256-76.

3. de Boer K, Vandemheen $\mathrm{KL}$, Tullis $\mathrm{E}$, et al. Exacerbation frequency and clinical outcomes in adult patients with cystic fibrosis. Thorax 2011;66:680-5.

4. Miller MR, Quanjer PH, Swanney MP, et al. Interpreting lung function data using $80 \%$ predicted and fixed thresholds misclassifies more than $20 \%$ of patients. Chest 2011;139:52-9.

5. Swanney $\mathbf{M}$, Ruppel $G$, Enright $P$, et al. Using the lower limit of normal for the $F E V_{1} / F V C$ ratio reduced the misclassification of airway obstruction. Thorax 2008;63:1046-51.

6. Contoli M, Baraldo S, Marku B, et al. Fixed airflow obstruction due to asthma or chronic obstructive pulmonary disease: 5-year follow-up. J Allergy Clin Immunol 2010;125:830-7

7. Wilkens H, Weingard B, Lo Mauro A, et al. Breathing pattern and chest wall volumes during exercise in patients with cystic fibrosis, pulmonary fibrosis and COPD before and after lung transplantation. Thorax 2010;65:808-14

8. Bush A, Pavord I. Following Nero: fiddle while Rome burns, or is there a better way? Thorax 2011;66:367.

9. Dijkstra A, Vonk JM, Jongepier $\mathrm{H}$, et al. Lung function decline in asthma: association with inhaled corticosteroids, smoking and sex. Thorax 2006:61:105-10.

10. Buist AS, McBurnie MA, Vollmer WM, et al; BOLD Collaborative Research Group. International variation in the prevalence of COPD (the BOLD Study): a populationbased prevalence study. Lancet 2007:370:741-50.

11. Gaillard EA, Shaw NJ, Wallace HL, et al. Electrical potential difference across the nasal epithelium is reduced in premature infants with chronic lung disease but is not associated with lower airway inflammation. Pediatr Res 2007;61:77-82.

12. Beyer D, Mitfessel $H$, Gillissen A. Maternal smoking promotes chronic obstructive lung disease in the offspring as adults. Eur J Med Res 2009:14(Suppl 4):27-31.

13. Hunninghake GM, Cho MH, Tesfaigzy $T$, et al. MMP12, lung function and COPD in high-risk populations. N Engl J Med 2009;361:2599-608.

14. Repapi E, Sayers I, Wain LV, et al. Genome-wide association study indentifies fie new loci associated with lung function. Nat Genet 2010;42:36-44.

15. Wan ES, Hokanson JE, Murphy JR, et al. Clinical and radiographic predictors of GOLD-unclassified smokers in COPDGene Study. Am J Respir Crit Care Med 2011; 184:57-63 